\title{
Lev Nikolayeviç Tolstoy'un “İnsan Ne İle Yaşar" Adlı Hikayesinin Değerler Eğitimi Açısından İncelenmesi
}

DOI: $10.26466 /$ opus.936472

\author{
Aynur Pala* \\ * Dr. Öğr. Üyesi, Manisa Celal Bayar Üniversitesi, Eğitim Fakültesi, Manisa/Türkiye \\ E-Posta: aynur pala@yahoo.com \\ ORCID: $\underline{0000-0003-4889-7438}$
}

\begin{abstract}
Öz
Değerler, milli ve küresel gelişime elverişli olan hayat prensiplerini yönlendiren, hayata yön, dayanma gücü, yaşama sevinci, mutluluk, huzur vb. getiren olgulardır. Değerler bir bireyin rayda kalmasinı ve yoldan çıkmamasını sağlayan raylar gibidir; yumuşak, hızl ve doğru hareket etmesine yardımcı olur. Değerlerin insan hayatında etkisi ve katkısı mutlaktır. Gerek gazetede, gerekse televizyonlarda hırsızlık, şiddet olayları, dolandırıcılık alkol ve madde bağımlılı̆̆g gibi olaylar ile ilgili çok fazla haberleri görmekteyiz. Dürüstlük gibi değerin aşılanmasıyla, hırsızlık, dolandırıcllık gibi olumsuz davranışların azalması beklenmektedir. Okullarda değer eğitimi ile ilgili farklı yöntemler kullanılmaktadır. Bunlardan birisi de masal, hikaye, roman gibi kitaplardaki karakterlerin incelenmesi ve tartışmaya açılmasıdır. Bu çalışmanın amacl, Rus yazar Lev Tolstoy'un 1885 yılında yazdığı ve aslından Sultan Bozdă̆ Özmen tarafindan Türkçe' ye çevirisi yapılan "Insan Ne İle Yaşar" hikayesinde yer alan değerlerin ortaya çıkarılmasıdır. Bu çalışmada niteliksel araştırma metotlarından biri olan doküman analizi yöntemi kullanılmıştır. Veriler içerik analizi yöntemi kullanılarak analiz edilmesi sonucunda, bu hikayede en belirgin olarak, kanaatkarlık, merhamet, diğgerkamlık, sevgi ve önyargılı olmama ve Tanrı inancı değgerleri göze çarpmaktadır. Bu açıdan öğrencilerin okuyacă̆ı bu eser, son zamanlarda gittikçe yitirilmekte olan ve en fazla ihtiyaç duyulan "sevgi" değeri üzerinde yoğunlaşmaya sebep olacağ̀ düşünülmektedir. "İnsan Ne ile Yaşar" hikayesinin özellikle ortaokullarda ve liselerde değer ve karakter eğitimi amactyla kullanılabileceği sonucuna varılmışıtır. Ayrıca, bu çalışmanın karakter ve değer eğ itimi ile ilgilenen ö̆̆retmenlere de bir katkı sağlayacă̆ı düşünülmektedir.
\end{abstract}

Anahtar Kelimeler: Değer Ĕ̆itimi, İnsan Ne ile Yaşar, Lev Tolstoy. 


\title{
Investigation of Lev Tolstoy's Story “What Men Live By" in terms of Values Education
}

\begin{abstract}
Values are the phenomenon that bring direction of life, endurance, joy of life, happiness, peace etc. Values are like rails that keep an individual on the track and stay on track; helps it move smoothly, quickly and accurately. Its effect and contribution in human life is also absolute. We see a lot of news on events such as theft, violence, fraud, alcohol and substance addiction, both in the newspaper and on the television. For example by teaching values of honesty, negative behaviors such as theft and fraud are expected to decrease. In this respect, it is thought that reading this work will cause to concentrate on the value of "love" which being lost and is the needed recently. Different methods of value education are used in schools. One of them is the examination and discussion of characters in books such as fairy tales, stories and novels. The aim of this research is to reveal the values in the story "What Men Live By" written by the Russian writer Lev Tolstoy in1885. As a result of analyzing the data with the method of content analysis, it was found that the most prominent values are austerity, compassion, altruism, love, nonprejudice and belief in God in this story. It was concluded that the sorry "What Men Live By" can be used for values education, especially secondary and high schools. It was thought that this study will be contribute to teachers who are interested in character and value education. In this respect, it is thought that this work that students will read will cause to concentrate on the value of "love", which is being lost and is most needed recently.
\end{abstract}

Keywords: Value Education, What Men Live By, Lev Tolstoy. 


\section{Giriş}

Gerek farklı ülkelerin eğitim sistemlerinde gerekse Türkiye'de karakter, değerler ve ahlak eğitiminin nasıl verilmesi, hangi yöntem ve tekniklerin kullanılması gerektiği, hangi yaklaşımların uygulanması gerektiği ile ilgili tartışmalar devam etmektedir Ahlak ve değer eğitimine yönelik yaklaşımlardan bazıları şunlardır:

- Değer Açıklama (Değer Belirginleştirme) Yaklaşımı

- Telkin yaklaşımı

- Ahlaki muhakeme

- Gözlem yoluyla öğrenme yaklaşımı

- Değer Analizi

- Örtük Program

- Model olma

- Hizmet ederek öğrenme yaklaşımı (Ulusoy, (2019).

Değer Açılama yöntemi ile verilmek istenen değer/değerlere yönelik rol oynama, drama, grup tartışması, açık uçlu sorular, biyografi, otobiyografi, görüşme, film, hikayeler, görsel materyaller kullanılarak değerlerler öğretilmektedir. Değer ile ilgili içerik, bir veya birkaç değeri destekleyici sınıf tartışmaları yapılmasına ve analiz edilmesine uygun olmalıdır. Son zamanlarda değer öğretimine önem artmakta ve okullardaki programlara değerler entegre edilmektedir. Ancak hangi değerler ve nasıl öğretileceği konusunda tartışmalar sürmektedir.

Değerler eğitiminde değerleri içeren roman, hikaye gibi metinler önemli yer tutmaktadır. Bu gibi kaynaklarla öğrencilerin ahlaki ve insani değerleri anlamalarına ve bu değerleri içselleştirmelerine yardımcı olabileceği düşünülmektedir. Değerler eğitimi uygulamalarında edebiyat eserlerinden yapılan okumalar, kurgu içerisinde değerin hissedilmesi, değerin farkına varılması, değerle ilgili bir görüş kazanılması açılarından önemli bir yer tutmaktadır (Yeniay, 2019).

Bu çalışmanın amacı, amacı L. Tolstoy'un "İnsan Ne İle Yaşar" adlı hikayenin değerler açısından incelemektedir. Bu araştırmada "kanaatkarlık, merhamet, diğerkamlık, sevgi ve önyargılı olmama ve Tanrı inancı gibi değerlerin öğretilmesinde "İnsan Ne İle Yaşar" hikayesi uygun mudur? sorusuna cevap aranmıştır. 
Öncelikle Lev Tolstoy'un kisaca hayatı ve eserlerine yer verilecektir. Daha sonra "İnsan Ne İle Yaşar" hikayesinin kısaca özeti verilerek ve hikayede yer alan değerler ortaya çıkarılacaktır.

Lev Tolstoy'un Hayatı: 28 Ağustos 1828 tarihinde, Moskova'nın güneyinde, asil bir ailenin çocuğu olarak doğan Tolstoy, uzun bir süre seyahat etmiş, tabiatı ve insanı incelemiştir. Batı'yı ve kendi ülkesini, insanlarını tanımış, yeni bir pedagoji sistemi geliştirmiştir. Tolstoy çağını çok iyi gözlemiştir. Aristokrat sınıfın amaçsız, debdebeli yaşantısına ateş püskürmüştür. Tolstoy'un kendini arayış serüveni ölünceye kadar sürmüştür.. Karısı bile onu anlamamış, bir çocuk gibi küsmüş ve kaçmıştır. Seksen iki yaşında iken, karanlık ve yağışlı bir Ekim gecesinde köyünden ayrılmış yolda hastalanmış ve 7 Kasım 1910' da küçük bir tren istasyonunda hayata veda etmiştir. İnsanın mutluluğu, ancak ahlaki yönden kendisini yetkinleştirmesinde bulabileceğini savunmuştur. Yazarlığının yanı sıra, gerek eserleriyle, gerek girişimleriyle eğitimci kişiliği ile de karşımıza çıkar. İçinde yaşadığı toplumun sosyo-ekonomik farklılıklarına savaş açan Tolstoy, "halkın eğitimi" konusunu en önemli görevlerinden biri olarak görür ve Rus köylüsünü eğitmek ve yaşantısını iyileştirmek adına çeşitli girişimlerde bulunur. Tolstoy romanlarında, insanoğlunun ne kadar değişik karakterli olduğunu vurgulamaktadır.

L. Tolstoy'un eserlerinden bazıları şunlardır: "İnancımın Niteliği" , "Dogmatik Din Biliminin Eleştirisi", Sanat Nedir , "Savaş ve Barış" ve Anna Karenina.

“ Insan Ne İle Yaşar" Hikayesinin Kısa Özeti: Ölüm gerçeğini, kıtlık, yoksulluk ve hastalıklardan dolayı ölen insanların hallerinde müşahede eden Lev Tolstoy bu hikayede dünyanın anlamını kavramaya çalışmış ve sürekli sorgulama çabası sergilemiştir. Fakir bir ayakkabıcının evinde bir ölümlü olarak yaşamaya başlayan bu meleğin, Tanrı'nın öğrenmesini emrettiği hakikatleri insanlar üzerinden öğrenme sürecini anlatır.

Ayakkabıcı olan Simon, içinde bulunduğu toplumda yaşayan diğer insanlardan oldukça farklı esrarengiz birisidir. Simon çok zor şartlarda yaşamaktadır. Buna rağmen çok cömerttir fakat Simon sürekli olarak aldatılmaktadır. Ancak, hiç bir zaman kibarlığından vazgeçmemektedir. 
İnsanlara veresiye ayakkabı yapmakta, fakat hiç kimse borcunu ödememektedir. Kendisi ve eşi için bir ceket diktirmek için kuzu postu almak üzere yola çıkar, borçlular borçlarını ödemediği için yeterli parayı toplayamaz ve postu alamaz. Fakat bu duruma çok da üzülmez "buna ihtiyacım yok, insanların koyun postundan ceketi olmasa da yaşayabilir» şeklinde düşünerek kendisini avutmaktadır.

Yolda yürürken bir şapelin yanında çıplak bir adamla karşılaşır. Önce korkar ve şüphelenir fakat sonra düşüncelerinden utanır üzülür ve kar1sıyla problem yaşayacağını bilmesine rağmen, bu adamın ona bakışından çok iyi kalpli bir olduğunu hisseder, geri döner üzerindeki paramparça ceketini ve ayakkabısını çıarır ve üşüyen adama giydirir. Adı Michael olan bu adama güvenerek evine davet eder. Eve gittiklerinde Simon'un karısı Matryona çok öfkelenir ve "İyi bir adam olsaydı çıplak olmazdı, üstünde gömlek bile yok" der. Fakat daha sonra kadın adama merhamet edip sonraki gün için yeterli yiyecek olmamasına rağmen Michael'e yemek verir. Michael ilk defa tebessüm eder.

Simon, Michael'e ayakkabıcılığı öğretir ve birlikte çalışmaya başlarlar. Bir gün zengin asil bir adam dükkana gelir ve bir sene kalıbının bozulmayacağı ve dikişlerinin sökülmeyeceği kalın bir çizme dikmesini ister. İstediği gibi olmazsa Simon'u tutuklatacağın belirtir. Michael ikinci defa gülümser. Michael kalın çizme yerine, yumuşak deri bir terlik diker. Simon niye böyle aptalca bir şey yaptığını Michael'e sorar. O sırada, bir kişi gelir çizme isteyen adamın öldüğü haberini verir ve ölüm yatağında giymesi için terlik istediğini söyler.

Başka bir gün bir kadın, ikiz çocuklar için terlik diktirmek üzere dükkana gelir. Kadın çocukların kendisinin olmadığını, yetim kaldıkları için onları acıyıp, kendi çocukları gibi baktığını söyler. Michael üçüncü kez gülümser.

Daha sonra, Simon, Michael'e üç kez gülümsemesinin sebebini sorar. Michael kendisinin melek olduğunu ve Tanrı'nın kendisini bir kadının ruhunu alması için gönderdiğini fakat kadının yalvarması üzerine O'na itaat etmediği için cezalandırıldığını ve dünyaya gidip hayatın üç gerçeğini öğrenmesini istediğini söyler. Michael ilk defa Simon ve eşinin kendisini evlerine davet ettiğinde gülümsediğini ve insanlara sadece kendi refahları için verdikleri uğraşla hayatta kalıyorlar gibi görünse de onların sa- 
dece sevgiyle hayatta kaldıklarını anladığını, insanın içinde sevgi barındırdığını öğrendiğini söyler. Michael ikinci defa çizme ısmarlayan adama söyledikleri karşısında gülümsediğinde, hayatın ikinci gerçeğini "Adam bir yıllık hazırlık yapıyor ama akşam olmadan öleceğinden haberi yok." O zaman İnsanlara kendi ihtiyaçlarının ne olduğu bilgisi bahşedilmemiştir. Onu öğrendim der. Michael üçüncü kez yetim ikizlerin bir yabancı tarafından kendi çocukları gibi baktığını görünce gülümser. Hayatın üçüncü gerçeğinin insanın anasız babasız yaşayabileceğini ama Tanrı'sız yaşanamayacağını anladığını belirtir. Ve sonunda Michael'in omuzlarından kanatlar açılır ve göğe yükselir.

\section{Yöntem}

Bu bölümde araştırma modeli, verilerin toplanması ve çözümlenmesi ile ilgili konulara yer verilmiştir.

\section{Araştırmanın Modeli}

"İnsan Ne İle Yaşar " adlı hikâye kitabında yer verilen değerleri belirlemek için nitel araştırma yöntemlerinden doküman incelemesi tekniği kullanılmıştır. Veriler içerik analizi yoluyla çözümlenmiştir. "İnsan Ne İle Yaşar" hikayesinin içeriği değerler açısından incelendiğinde, kitapta en belirgin olarak, kanaatkarlık, merhamet, diğerkamlık, sevgi ve önyargılı olmama ve Tanrı inancı göze çarpmaktadır.

\section{Verilerin Toplanması ve Çözümlenmesi}

Araştırmaya konu olan verilerin toplanmasında nitel araştırma yöntemlerinden doküman incelemesi kullanılmıştır. Doküman incelemesi bilgi içeren yazılı kaynakların olgu veya olguları hakkında analiz sürecini kapsar (Yıldırım ve Şimşek, 2018). Araştırmada Rus Yazar Lev Tolstoy'un yazdığg ve Sultan Bozdağ Özmen tarafından Rusça aslından çevirisi yapılan "İnsan Ne İle Yaşar" hikâye kitabı temel alınmıştır. Kitap, Kayalıpark Yayınları tarafından 2017 yılında basılmıştır. Kitapta bu hikayenin sayfa sayısı 48 dir. Kitapta ayrıca "İnsana Çok Toprak Gerekir mi?, “Efendi ile Uşağı" ve "Üç Soru” adlı hikayeler de bulunmaktadır. 
Araştırmaya konu olan kitap araştırmacı tarafından birkaç kez okunması sonucunda "İnsan Ne İle Yaşar" adlı hikâye kitabında değerler ile ilgili olgu ya da olgulara ilişkin bilgi içeren cümlelerde değerler belirlenmiştir. Bu değerler bulgular kısmında sunulurken "İnsan Ne İle Yaşar" hikâye kitabında yer alan alıntılara yer verilmiştir.

Nitel araştırmalarda güvenirliği artırmak için yöntemlerden birisi de uzman görüşü alınmasıdır. Bu çalışmada bu konu hakkında genel bilgisi olan Psikolojik Danışmanlık ve Rehberlik bölümü bir öğretim üyesinin görüşü alınmıştır. Ayrıca "İnsan Ne ile Yaşar" hikayesinin yorumları ile ilgili literatür taraması yapılmıştır.

\section{Bulgular}

Değerler bağlamında incelenmesi amaçlanan bu çalışmada, araştırma sorusu kapsamında taranan 48 sayfalık hikâye kitabında kazandırılması hedeflenen beş adet farklı değer tespit edilmiştir. "İnsan Ne İle Yaşar" kitabında tespit edilen değerler ve ilgili ifadeler şunlardır:

1- Kanaatkarlık: Simon parası yetmediği için kuzu postu alamaz fakat "Gocuğa ihtiyacım falan yok. Derdimi unutmuş gidiyorum. Böyle bir adamım işte! Neme gerek? Gocuk olmadan da yaşarım. Hiç ihtiyacım yok." Evde ekmek olmamasına karşlık Simon "Yarın ölmez de sağ kalkarsak yiyecek bir şeyler buluruz".

2- Merhamet ve Diğerkamlı: Simon önce Michael'e "Allah yardım etsin" şeklinde düşünmüş ancak vicdanı el vermeyip "Sen ne yapıyorsun Simon, adam çaresizlik içinde ölüyor, sen ise korkup adamı oracıkta bırakıyorsun" Yoksa servetinin soyulmasindan korkacak kadar zengin mi oldun? Ah Simon, yazık sana." diye düşünür ve yardım için geri döner. Simon Michael'e "birlikte benim evime gidelim" diyerek merhamet eder. Kendisi de üşümesine rağmen "Şu kaftanı giy önce! Haydi! diyerek kaftanın kollarını geçirdi. Düzeltip önünü kavuşturdu ve kuşağını sıktı. Adamı oturttu ve çizmeleri giydirdi. "İşte oldu, kardeş. Haydi, biraz ısın bakalım. Diğer meseleler sonra da çözülür. O hâlde birlikte benim evime gidelim. Hiç olmazsa biraz kendini toparlarsın" dedi". Matryona kalbi birden yumuşamıştı. Kapıdan geri döndü, sobanın olduğu köşeye geçti, yiyecek bir şeyler çıardı. Matryona yolcuya acımış ve sevgi duymaya başlamıştı. 
Matryona kalktı, pencereden az önce yamadığı eski gömleği aldı, yolcuya verdi. Bir de pantolon bulup verdi.

İkizler ile dükkana gelen kadın : «Ben onların ne annesiyim, ne de akrabaları. Hiç yakınlığımız yok, onları evlatlık aldım. Kendi çocuklarım değil ama onlara hiç kıyamıyorum, nasıl kıyayım, yetim kalan ikisini de ben emzirip büyüttüm. Ama sonra kendi kendime düşündüm, bu masum neden acı çeksin."

3- Sevgi: Simon: "İnsanlara sadece kendi refahları için verdikleri uğraşla hayatta kalıyorlar gibi görünse de onların sadece sevgiyle hayatta kaldıklarını anladım. İçinde sevgi barındıran kişi Tanrı'ya yakındır, Tanrı onun içindedir, çünkü Tanrı sevgiyi yaratandır" Matryona yolcuya acımış ve sevgi duymaya başlamıştı.

4- Önyargı: Simon'un eşi Michal'i görünce “İyi bir adam olsaydı çılak olmazdı, üstünde gömlek bile yok. Diyelim ki iyi bir sebepten geldi, söyle o zaman böyle bir züppeyi nereden bulup getirdin?, yanında çıplak bir serseri getirdin. Benden sizin gibi ayyaşlara yemek falan yok."

5- Tanrı inancı: Simon'un karısı Matryona'nın Michael'e karşı önyarg1sina karşılık “Tanrı'dan korkmuyor musun hiç? Biraz sakinleş. Günahtır, Matryona. Hepimiz öleceğiz bir gün. Matryona, Tanrı'dan korkmuyor musun hiç?" dedi. "Babasız anasız yaşanır ama Tanrı'sız yaşanmaz" İşte o zaman Tanrı'nın diğer emrini hatırladım: “

\section{Sonuç, Tartışma ve Öneriler}

L. Tolstoy'un "İnsan Ne ile Yaşar" hikayesinde yer alan belli başlı değerlerin kanaatkarlık, merhamet, diğerkamlık, sevgi ve önyargılı olmama ve Tanrı inancı değerleri olduğu görülmektedir. Bu değerler hikayenin ana karakterleri Michael, Simon ve Matryona'nın sözleri araciyla verilmektedir. "İnsan Ne ile Yaşar" hikaye kitabının değerler eğitimi açısından ortaokul ve lise öğrencileri için kaynak bir kitap olarak yararlanılabileceği sonucuna varılmıştır. Bu hikayede bu değerler genellikle nasihat etme şeklinde değil de örtük bir şekilde verilmiştir. Değerlerin günümüzde ne kadar çok önem kazandığını dikkate aldığımızda, değer aktarımı konusunda Tolstoy'un etkileyici bir üslupla yazılmış olan bu eserinden yararlanılabileceği söylenebilir. Öğrenciler, Tolstoy'un kitaplarını okumaları 
sonucunda hem okuma alışkanlığı kazanmalarında hem de bu değerler üzerinde düşünmelerine yol açabileceği söylenebilir.

Eğitim Fakülteleri'nde zorunlu bir ders olarak yer alan "Eğitimde Ahlak ve Etik" ve Psikolojik Danışma ve Rehberlik Programında yer alan" Karakter ve Değer Eğitimi" derslerinde öğretmen adaylarının bu ve değer eğitimiyle ilgili diğer eserlerin incelenmesi yoluyla değer öğretimi konusunda farkındalıklarının artmasında rehber olabilirler. Öğrencilerin yaşlarına uygun seviyede ve ilgilerini çekecek çeşitli hikâyeler, romanlar ve masallar gibi eserler seçilerek değerler eğitimine katkıda bulunmaları mümkün olabilsceği düşünülmektedir. 
EXTENDED ABSTRACT

\title{
Investigation of Lev Tolstoy's Story "What Men Live By" In Terms of Values Education
}

\author{
Aynur Pala \\ Manisa Celal Bayar University
}

Values are core beliefs that guide our attitudes and actions. They help us determine what is right or wrong and what is important to us. Values education is deliberate efforts based on fundamental values such as honesty, responsibility, cooperation, self-discipline and respect. Our society's present and future success depends on the virtue and morality of its people. Values teaching can be a solution to problems in many areas such as character education, student absenteeism, disciplinary problems, drug use, resorting to violence and academic failures.

Discussions continue about how values education should be given, which methods and techniques should be used, and which approaches should be applied both in the education systems in different countries and Turkey. Different methods of value education are used in schools. Some of the approaches are Incultion, Value clarification, Moral Development, Value Analysis and Action Learning. The other technique of them is the examination and discussion of characters in books such as fairy tales, stories and novels. It is thought that such resources can help students understand moral and human values.

The aim of this research is to reveal the values in the story "What Men Live By" written by the Russian writer Lev Tolstoy in 1885 and translated by Sultan Bozdağ Özmen. The number of pages of story is book.

Document analysis method which is one of the qualitative research methods was used to determine the values included in the story book called "What men live by". As a result of reading the story several times by the researcher, values were determined in the story titled "What men Live By "and presented in findings section with quotations.

As a result of analysing the data with the method of content analysis, it was found that the most prominent values are austerity, compassion, altruism, love, non-prejudice and belief in God. These values are given 
through the words of the main characters of the story. Michael, Simon and Matryona. These values are usually given implicitly, not in the form of advice.

Most prominently values examples and quotations are as follows:

1- Austerity: Simon can't buy sheep-skins in order to sew a winter coat for his wife and himself to share. "I don't need a coat. I'm going to forget my troubles. I am such a man'. What do you need? I can live without a coat. I don't need any. Despite the lack of bread at home, Simon said, "If we do not die tomorrow and we survive, we will find something to eat".

2- Compassion and Altruism: Simon first thought to Michael, "God may help him" but his conscience did not allow him to say, "What are you doing, Simon, the man dies in despair, you are afraid and leave the man there" Simon takes pity on Michael, saying, "Let's go to my house together" Although he was cold himself, he said, "Put that robe first! Let's he said, crossing the sleeves of his robe. He made the man sit down and put on the boots. "Brother, come on, let's warm up a little" The woman who came to the shop with the twins: "I am neither their mother nor their relatives. We're not close at all, I adopted them. It's not my own children, but I can't hurt them, how can leave them. I nursed and raised both of them who were orphaned"

3- Love : Simon: "I realized that although it seems that people only survive by striving for their own well-being, they only can survive by love.",

4- Prejudice: When Simons's wife saw Michael, she said, "If he was a good man, he wouldn't be naked, he doesn^t even a shirt on. "Matryona took pity on the traveller and began Let's say it came for a good reason, then tell me, where did you find such a snob, to feel love."

5- Belief in God: Simon: "Matryona, do you not fear God? , "Calm down a little. It is a sin, Matryona. We will die one day. It is possible to live without a father and mother, but not without God."

It has been concluded that this story book can be used as a source book for secondary and high school students to teach values. It can be said that as a result of reading books, students both gain reading habits and think about basic values. Also it is thought that in compulsory courses such as 
"Morality and Ethics in Education" and "Character Education" , at Faculties of Education, books included values may increase awareness of values of pre-service teachers.

\section{Kaynakça / References}

Tolstoy, L.N. (2017). İnsan ne ile yaşar. (Çev.S.B. Özmen). Konya: Sebat Ofset. Ulusoy, K. (2019). Karakter değerler ve ahlak eğitimi. Ankara: Pegem Akademi. Yeniay, S. (2019). Behiç AK'ın hikâyelerinin değerler eğitimi açısından incelenmesi. adlı Yüksek Lisans Tezi. Necmettin Erbakan Üniversitesi, Eğitim Bilimleri Enstitüsü, Konya.

Yıldırım, A. ve Şimşek, H. (2018). Sosyal bilimlerde araştırma yöntemleri. Ankara: Seçkin Yayıncılık.

\section{Kaynakça Bilgisi / Citation Information}

Pala, A. (2021). Lev Nikolayeviç Tolstoy'un "İnsan Ne İle Yaşar" adlı hikayesinin değerler eğitimi açısından incelenmesi. OPUS-Uluslararası Toplum Araştırmaları Dergisi, 18(44), 8420-8431.DOI: 10.26466/opus.936472. 